\title{
An automated system for selective and continuous measurements of vertical thoron profiles for the determination of transport times near the ground
}

\author{
D. Plake and I. Trebs \\ Max Planck Institute for Chemistry, Biogeochemistry Department, P. O. Box 3060, 55020 Mainz, Germany \\ Correspondence to: D. Plake (daniel.plake@mpic.de)
}

Received: 14 December 2012 - Published in Atmos. Meas. Tech. Discuss.: 25 January 2013

Revised: 25 March 2013 - Accepted: 26 March 2013 - Published: 16 April 2013

\begin{abstract}
The quantification of in-canopy transport times is of major importance for the investigation of sources, sinks and net fluxes of reactive trace gases within plant canopies. The Damköhler number, which compares timescales of chemical reactions with transport times, is a widely applied measure to evaluate flux divergences. In this study we present and evaluate a novel automated measurement system for selective vertical thoron (Tn) profiles near the Earth's surface and demonstrate its suitability for the direct and reliable determination of transport times within a natural grassland canopy. For the first time, we perform a rigorous determination of systematic and random uncertainties of $\mathrm{Tn}$ (and $\mathrm{Rn}$ ) concentrations under field conditions for this type of measurement system. The obtained median precisions for three concentration classes $\left(>100 \mathrm{~Bq} \mathrm{~m}^{-3}, 100-15 \mathrm{~Bq} \mathrm{~m}^{-3}\right.$, $<15 \mathrm{~Bq} \mathrm{~m}^{-3}$ ) were $8.8 \%, 23.2 \%$ and $132.1 \%$ for Tn (and $16.6 \%, 25.0 \%, 99.2 \%$ for $\mathrm{Rn})$. We calculate in-canopy transport times $(\tau)$ and propagate their uncertainty from the individual errors of the Tn concentration measurements. A quality assessment of $\tau$ for the field experiment during a period of 51 days revealed good data quality with $44 \%$ of the relative uncertainties below $50 \%$. The occurrence of transport time uncertainties higher than $100 \%$ was caused by absolute $\mathrm{Tn}$ gradients lower than $70 \mathrm{~Bq} \mathrm{~m}^{-3} \mathrm{~m}^{-1}$, which was found for $22 \%$ of all determined transport times. In addition, the method was found to be highly sensitive to the Tn concentrations at the upper of the two inlet heights $\left(z_{\mathrm{u}}\right)$. Low values of $C_{\mathrm{Tn}_{z \mathrm{u}}}$ result in high absolute uncertainties of the transport time. A comparison with empirical parameterizations revealed a much lower scatter for the $\tau$ values determined from our measurements. We found an excellent agreement
\end{abstract}

with $\tau$ values obtained by the in-canopy resistance approach used, e.g., in the SURFATM model during daytime, while the SURFATM model significantly overestimated transport times during nighttime.

\section{Introduction}

The two isotopes ${ }^{220} \mathrm{Rn}$ (thoron) and ${ }^{222} \mathrm{Rn}$ (radon) are generated in rocks and natural soils, where their respective mother nuclides thorium $\left({ }^{232} \mathrm{Th}\right)$ and uranium $\left({ }^{238} \mathrm{U}\right)$ occur as common radioactive atoms. Thoron $(\mathrm{Tn})$ and radon $(\mathrm{Rn})$ can migrate into the atmosphere if the location of the production is close enough to the soil-atmosphere interface. The half-life times $\left(T_{0.5}\right)$ are $55.6 \mathrm{~s}$ for $\mathrm{Tn}$ and $3.8 \mathrm{~d}$ for Rn (Lide, 2004) and limit the transport distances within the soil and the atmosphere. Above the soil, $\mathrm{Tn}$ and $\mathrm{Rn}$ atoms undergo dilution and transport in atmospheric air until they are removed by radioactive decay, which is their only removal process. In flat terrains with homogeneous emission rates, $\mathrm{Tn}$ and $\mathrm{Rn}$ concentrations therefore always decrease with height. Due to its relatively long $T_{0.5}, \mathrm{Rn}$ is widely used as tracer for regional and global atmospheric transport (cf. Dorr et al., 1983; Zahorowski et al., 2004) and in global circulation models (cf. Brost and Chatfield, 1989; Zhang et al., 2008). In contrast, $\mathrm{Tn}$ is excellent for studying meteorological processes in the lowest decameters above soil (Israel, 1965).

Soil is to a large extent covered by plant canopies, such as forest, crop or natural grassland, which act as sources and sinks of reactive trace gases. Canopies strongly influence the vertical wind profile and other micrometeorological 
parameters, which drive the trace gas exchange (cf. Finnigan, 2000). The first meter above soil is of significant importance for the surface-atmosphere exchange fluxes of trace gases since the eddy diffusivity $(K)$ changes by three orders of magnitude (cf. Ikebe and Shimo, 1972) and the transition from turbulent to diffusive transport occurs. The transport time of the air within this layer determines the effectiveness of (a) chemical reactions and inter-conversion of reactive trace gases (termed "chemical flux divergence"; De Arellano et al., 1993) and (b) the deposition and uptake to/by plants and soil of either the directly emitted compounds or their reaction products. For instance, due to long in-canopy transport times, only a fraction of soil biogenic nitric oxide (NO) emissions may leave a canopy because a large part is oxidized by ozone $\left(\mathrm{O}_{3}\right)$ and the product nitrogen dioxide $\left(\mathrm{NO}_{2}\right)$ is subsequently recaptured mainly through uptake by soil and plant stomata ("canopy reduction") (e.g., Yienger and Levy, 1995). The calculation of Damköhler numbers, which compare chemical timescales to transport times $(\tau)$, is a widely applied approach to evaluate the influence of chemistry on exchange fluxes (e.g., Dlugi et al., 2010). Typically, $\tau$ or $K$ may be derived using micrometeorological techniques such as the eddy covariance and the flux-gradient approach. However, their application is limited within plant canopies where low turbulence prevails and, e.g., the Monin-Obukov similarity theory does not hold (Denmead and Bradley, 1985). In addition, practical reasons complicate their in-canopy application (e.g., short distance between wind sensors and branches).

Radon is mainly used as a tracer in studies focusing on vertical spatial scales of meters to kilometers above soil (e.g., Liu et al., 1984). Some studies present mean residence times for tall forest canopies (e.g., Trumbore et al., 1990; Ussler et al., 1994; Martens et al., 2004) derived using Rn canopy inventory models (for details see Trumbore et al., 1990). A similar method was used by Simon et al. (2005), who calculated vertical $\tau$ profiles from $\mathrm{Rn}$ measurements inside a rainforest canopy.

In contrast, studies dealing with Tn mainly focus on the layer adjacent to the ground, where its concentration is determined by the competition of transport and the fast radioactive decay. Decay of Rn can be neglected in this layer because of its longer $T_{0.5}$. Butterweck et al. (1994) point out that even in a dense canopy, where most micrometeorological methods fail, the turbulent exchange can be characterized with the help of Tn. Lehmann et al. (1999) describe the characteristic vertical range for $\operatorname{Tn}\left(z^{*}=(K / \lambda)^{1 / 2}\right.$, where $\lambda=\ln 2 / T_{0.5}=$ $0.0125 \mathrm{~s}^{-1}$ is the radioactive decay rate (Hänsel and Neumann, 1995) and $K=10^{-3} \mathrm{~m}^{2} \mathrm{~s}^{-1}$ ) to be $28 \mathrm{~cm}$. Furthermore, they propose a straightforward method to determine effective transport times from vertical Tn profiles near the ground as

$\tau=\ln \left[\frac{C_{\mathrm{Tn}_{z_{1}}}}{C_{\operatorname{Tn}_{z_{u}}}}\right] / \lambda$, where $C_{\mathrm{Tn}_{z_{1}}}$ and $C_{\mathrm{Tn}_{z_{u}}}$ are the measured Tn concentrations at the lower and upper heights $\left(z_{1}\right.$ and $\left.z_{\mathrm{u}}\right)$. These authors call this approach a perfect tool for studying near-surface gas transport under stable situations when more conventional micrometeorological methods are not applicable. The Tn tracer technique is independent of any particular transport model and the required physical information is entirely provided by the "Tn clock".

General prerequisites for the application of Lehmann's method are homogeneity of the Tn emission and reasonable flatness of the terrain. From the technical point of view, the major limitation is the precision of the Tn measurement, which has not been investigated under field conditions up to now. Typically, two Tn and Rn monitors (AlphaGuard, Saphymo GmbH, Frankfurt, Germany) were operated in series. Since one AlphaGuard analyzer measures the sum of $\mathrm{Tn}$ and $\mathrm{Rn}$, the isotope separation is made by a defined $\mathrm{Tn}$ decay volume installed between the two AlphaGuards. The Tn concentration is then obtained by subtraction of the Rn signal (2nd AlphaGuard) from the sum of Tn and Rn (1st AlphaGuard). Gut et al. (2002), Hens (2009) and Nemitz et al. (2009) applied the same technical setup above a rain forest floor, above a spruce forest floor and within a grassland canopy, respectively. However, none of these studies include a determination of systematic errors between the two AlphaGuards, nor do they estimate random concentration errors. Consequently, the uncertainties of the derived $\tau$ values in Lehmann et al. (1999), Hens (2009) and Nemitz et al. (2009) are unknown. In addition, the three measurement heights of the profile in these studies were sequentially switched (time resolution: $10 \mathrm{~min}$ sampling per hour and height). Thus, the vertical concentration profiles may be prone to non-stationarities.

In this paper we present a novel automated system for selective Tn and Rn profile measurements consisting of three $\mathrm{Tn}$ and $\mathrm{Rn}$ monitors. We show measured vertical $\mathrm{Tn}$ and $\mathrm{Rn}$ concentration profiles within a grassland canopy. The influence of non-stationarities is minimized by continuous and simultaneous measurements at three heights. For the first time, a rigorous determination of systematic and random uncertainties for $\mathrm{Tn}$ and $\mathrm{Rn}$ concentrations measured under field conditions is made. Due to the outstanding advantages of using $\mathrm{Tn}$ to directly determine $\tau$ near the ground (see above), we particularly focus our further analyses on Tn. Transport times are calculated from the vertical Tn concentration profiles and the corresponding random concentration errors are propagated in order to quantify the overall uncertainty of $\tau$. We compare quality assessed $\tau$ values with empirical parameterizations used in surface-atmosphere exchange models. 


\section{Methods}

\subsection{Radon and thoron monitor}

The concentrations of $\mathrm{Tn}$ and $\mathrm{Rn}$ were measured with three commercially available radon monitors (RAD7, Durridge, Billerica, USA). The RAD7 uses a solid-state alpha detector for alpha particle counting and electronic alpha spectrometry for differentiation between Tn and $\mathrm{Rn}$. In the sample air, alpha particles of different electric charges are emitted as Tn and $\mathrm{Rn}$ decay products. The alpha radiation is converted in the RAD7 measurement chamber to an electric signal and its energy is determined. The RAD7 records a spectrum of the incoming alpha particle energies over a chosen integration time and can distinguish $\mathrm{Rn}$ from $\mathrm{Tn}$, which is very rare for currently available commercial $\mathrm{Rn}$ monitors.

The RAD7 was developed for locating Tn and Rn entry points in basements of buildings and monitoring of mining galleries, i.e., environments with high Tn and Rn concentrations. Our RAD7 monitors were modified in order to meet the requirements of continuous profile measurements in a grassland ecosystem, with relatively low Tn and Rn concentrations. The sensitivity was enhanced by using a high-gain modification provided by the manufacturer consisting of (a) an increased size of the measurement chambers $(0.95 \mathrm{~L})$ and (b) alpha detectors with a larger active surface area. In cases when a fast Tn response is required in a standard operation mode, the RAD7 is run in "Sniff mode" with a nominal onboard pump flow rate of $0.65 \mathrm{~L} \mathrm{~min}^{-1}$. This low flow rate promotes the reduction of the Tn signal due to fast Tn decay during transport from the sampling point to the RAD7 measurement chamber. To diminish this effect we used an external pump and a mass flow controller (MFC) and set the flow rate to $2 \mathrm{~L} \mathrm{~min}^{-1}$. In addition, precise measurements with a RAD7 require atmospheric pressure conditions and a relative humidity $(\mathrm{RH})$ below $10 \%$ in the measurement chamber.

\subsection{System setup and configuration}

The automated Tn and Rn profile system (Fig. 1) consists of three identical inlet tubes. The hardware components are described in detail in Table 1. The inlet prevents the aspiration of rain drops and particles into the system and is made of a funnel and a membrane filter (Fig. 2a). Sensitive electronic parts like the RAD7s, pumps, MFCs and data recording units are installed in a rack (Fig. 2b) and protected by a waterproof housing. The air is drawn through PFA tubing $(\mathrm{L}=6 \mathrm{~m})$ from the inlets to the RAD7 monitors in the housing. The tubing is heated above ambient temperature and isolated to avoid condensation of water vapor. In-tubing pressures are permanently monitored upstream of the pumps (see Fig. 1). To achieve the required low RH in the RAD7 monitors, Nafion dryers are installed between pumps and MFCs and are operated at high pressure. Three Nafion dryers are used in parallel for each inlet height. Downstream of the MFCs, atmospheric

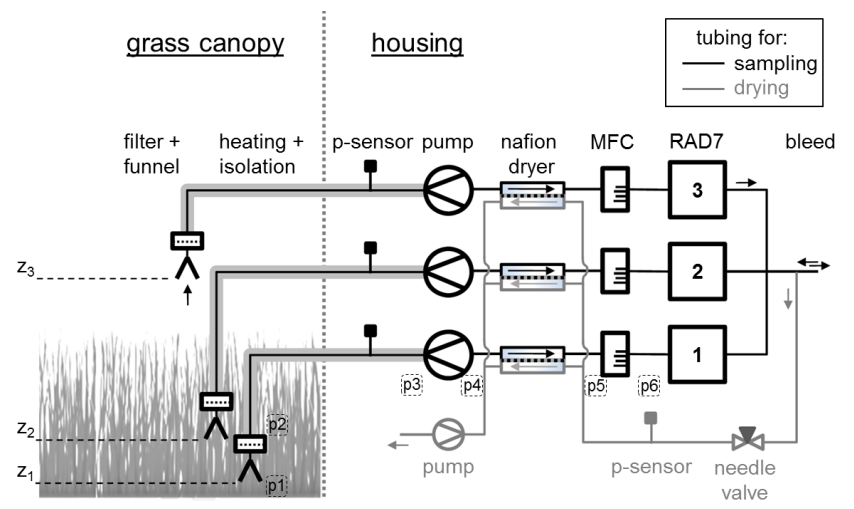

Fig. 1. Simplified gas flow scheme of the automated Tn and Rn profile system. The positions of the pressure measurements (p1-p6) mentioned in Sect. 2.4.1 are indicated.

pressure conditions are achieved by using an open bleed line. The drying purge for the Nafions is operated using the highly efficient reflux method. Hence, a part of the previously dried RAD7 exhaust is flushed counter flow back into the underpressurized drying purge (see Fig. 1). The pressure difference between the sample flow/Nafion and the drying purge is about $2000 \mathrm{hPa}$.

The RAD7 contains an onboard data logger and a RS232 interface. Data are downloaded using the manufacturer software "Capture" on demand. A home-built V25 microprocessor unit collects, e.g., the data from the pressure sensors of the Tn and Rn profile system and from a vertical thermocouple profile (ASPTC, Campbell Scientific, Utah, USA). Specially programmed Labview software running on a master $\mathrm{PC}$ requests every $10 \mathrm{~s}$ the data from the V25 via RS232 connection. The MFC flow rates are monitored periodically with the Labview software.

\subsection{Application in the field}

The field measurements to test and validate the system were made from July to September 2011 in Rhine-Hesse (Germany) at the estate of the Mainz Finthen Airport $\left(49.9685^{\circ} \mathrm{N}, 8.1481^{\circ} \mathrm{E}\right)$. The vegetation type is classified as a nutrient poor steppe-like grassland ecosystem with a mean canopy height of $0.6 \mathrm{~m}$. A continuous Tn and Rn profile data set of 51 days is available (6 August-25 September 2011). The integration time of the RAD7 monitors was set to $60 \mathrm{~min}$. The vertical wind speed profile was measured at heights of $0.2 \mathrm{~m}, 0.8 \mathrm{~m}, 1.5 \mathrm{~m}, 2.5 \mathrm{~m}$ and $4.0 \mathrm{~m}$ (2D ultra sonic anemometer, WS425, Vaisala, Finland). In addition, the three-dimensional wind vector and temperature were measured at $20 \mathrm{~Hz}$ by a sonic anemometer (CSAT3, Campbell Scientific) located at $3.0 \mathrm{~m}$ above ground and recorded using a data logger (CR3000, Campbell Scientific). The friction velocity $\left(u_{*}\right)$, sensible heat flux $(H)$ and stability parameters were calculated using the eddy-covariance software TK3 (see Mauder and Foken, 2011). 


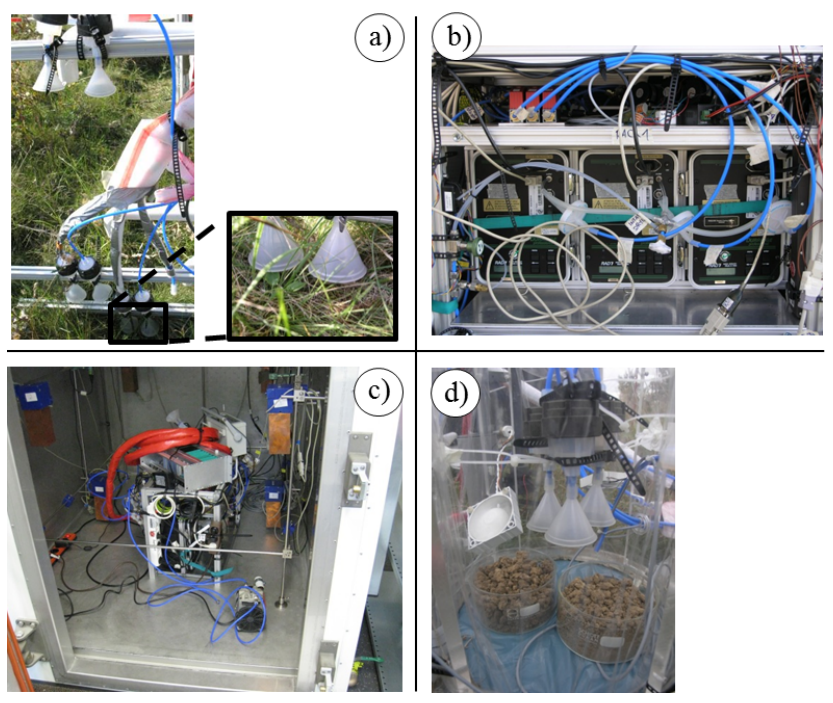

Fig. 2. Setup of the automated Tn and Rn profile system: (a) field installation of the inlets, (b) rack installation of the system in the housing, (c) setup in the thoron progeny chamber of the PTB in Braunschweig, (d) arrangement of inlets and soil samples during the side-by-side measurements in the dynamic chamber.

The arrangement of the inlet heights was varied throughout the field experiment (Fig. 3). Although the vertical inlet separation should be maximal in order to increase the observed vertical concentration differences, this approach is restricted due to the short $T_{0.5}$ of Tn. A more compact inlet arrangement close to the soil (e.g., Fig. 3, block 2) might be favored since all Tn may nearly be decayed just above the canopy.

\subsection{System characterization}

\subsubsection{Tn decay versus system residence time}

Due to the short half-life time of Tn, the radioactive decay during the residence time of the sample air in the system may significantly reduce the measured $\mathrm{Tn}$ concentration. A major prerequisite for reliable simultaneous Tn profile measurements with more than one analyzer is therefore the achievement of identical residence times in all sample lines. A constant flow rate in our setup is maintained by using precise MFCs. Nevertheless, vertical profile measurements can cause inhomogeneous clogging of the membrane filters used in the different sampling heights, which in turn might cause different residence times. To investigate the decrease of the Tn concentration in our system and to characterize the possible effect of filter clogging we proceeded in three steps: (i) pressure characterization with filter clogging simulation by using a needle valve, (ii) calculation of residence times from measured flow rates and pressures for laboratory and field conditions, and (iii) laboratory measurement of in situ system residence times.

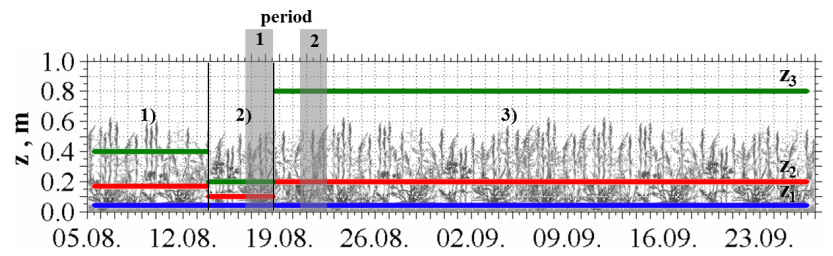

Fig. 3. Arrangement of the inlet heights $\left(z_{1}-z_{3}\right)$ for the automated $\mathrm{Tn}$ and $\mathrm{Rn}$ profile measurements with respect to the canopy height $h_{\mathrm{c}}$. The periods 1 and 2 treated in the data evaluation are indicated. The measurement campaign was divided into three blocks: (1) 513 August: $z_{1}=0.04, z_{2}=0.17, z_{3}=0.40 \mathrm{~m}$; (2) 13-18 August: $z_{1}=0.04, z_{2}=0.1 \mathrm{~m}, z_{2}=0.20 \mathrm{~m}$; (3) 18 August-26 September: $z_{1}=0.04, z_{2}=0.20, z_{3}=0.80 \mathrm{~m}$.

The pressure in our system was measured at six different positions (p1-p6) indicated in Fig. 1. Initially, pressures were measured at all positions using a clean filter. This procedure was repeated with the filter replaced by a needle valve to simulate the filter clogging states of clean (p2 $=980 \mathrm{hPa})$, medium (p2 $=960 \mathrm{hPa})$ and dirty $(\mathrm{p} 2=920 \mathrm{hPa})$ in the laboratory. Subsequently, the residence time was calculated for the three filter clogging states based on the continuity equation using the specific dimensions of all hardware components (e.g., tubing length and ID), the in-system pressures (p1-p6) and the volume flow rate at the MFC. In each part of the system, the actual volume flow rate was calculated followed by the determination of section specific residence times. The total system residence time was calculated by summing up the individual residence times. The same procedure was applied for the field campaign data set.

The system residence time was measured by replacing the RAD7 with a fast-response $\mathrm{CO}_{2}$ analyzer (LICOR7000, Licor Biosciences, Lincoln, USA). $\mathrm{CO}_{2}$ data were recorded in $0.5 \mathrm{~s}$ intervals. Upstream of the inlet system a three-way valve was installed, which controlled the flushing of the tubes with either zero air $\left.(0 \mathrm{ppm} \mathrm{CO})_{2}\right)$ or ambient air $(\sim 390 \mathrm{ppm}$ $\mathrm{CO}_{2}$ ). After flushing the line with zero air for some time, ambient air was sampled for one second, followed by sampling zero air again. The time that has passed between switching to ambient air and the maximum of the recorded $\mathrm{CO}_{2}$ peak is defined as the residence time with a clean filter.

The results of the calculations of the residence times under laboratory and field conditions and the in situ measurement were then compared to quantify the decay of $\mathrm{Tn}$ in the system and to evaluate the effect of inhomogeneous filter clogging.

\subsubsection{Tn sensitivity}

The RAD7 monitors were calibrated by the manufacturer only for Rn. A predefined sensitivity was applied for Tn, which is half of the Rn sensitivity. To ensure the accuracy of the Tn measurements, we verified the sensitivity before starting the field measurements. The entire measurement system was set up in the thoron progeny chamber (Fig. 2c) of 
Table 1. Details of the hardware components used for the automated Tn and $\mathrm{Rn}$ profile system.

\begin{tabular}{|c|c|c|}
\hline Part & Manufacturer & Specifications \\
\hline Inline filter case & Entegris Inc., USA & Galtek Integral Ferrule in-line filters \\
\hline Membrane filter & Pall Corporation, USA & $\begin{array}{l}\text { Zylon membrane disc filters, model P4PH047, pore size } 5 \mu \mathrm{m} \text {, } \\
\text { diameter } 47 \mathrm{~mm}\end{array}$ \\
\hline PFA tubing & $\begin{array}{l}\text { Saint-Gobain Performance Plastics } \\
\text { Isoflour GmbH, Germany }\end{array}$ & inner diameter (ID) $4 \mathrm{~mm}$, outer diameter $6.35 \mathrm{~mm}$ \\
\hline Tube heating & AEG Haustechnik, Germany & heating wire, type SLH 15 \\
\hline Pressure sensor & Sensor Technics, Germany & $\begin{array}{l}600-1100 \mathrm{hPa} \\
\text { type HDI0611ARY8P5 }\end{array}$ \\
\hline Sample pump & KNF Neuberger, Germany & $\begin{array}{l}\text { membrane pump, } \\
\text { type DCB24V N86KTDCB }\end{array}$ \\
\hline Nafion dryer & Perma Pure, USA & length $3.55 \mathrm{~m}$, ID $2.18 \mathrm{~mm}$, type PPMD-110-144F \\
\hline MFC & Vögtlin, Switzerland & $\begin{array}{l}\text { range } 0.05-5 \mathrm{~L} \mathrm{~min}^{-1} \text {, precision } 0.3 \% \text {, type Red-y smart controller } \\
\text { GSC-B hi-performance }\end{array}$ \\
\hline RAD7 & Durridge, USA & Tn and $\mathrm{Rn}$ monitor, range $\mathrm{Rn}: 4-400000 \mathrm{~Bq} \mathrm{~m}^{-3}$ \\
\hline Drying pump & $\begin{array}{l}\text { Gardner Denver, Thomas } \\
\text { Subdivision, USA }\end{array}$ & type: $607 \mathrm{CD} 22$ \\
\hline Needle valve & Kurt J. Lesker Company, USA & type: Nupro SS-SS4 \\
\hline
\end{tabular}

the radon measurement technique group at the PhysikalischTechnische Bundesanstalt (PTB, Braunschweig, Germany). This group at the PTB developed and operates the world's first primary standard for Tn activity concentration in air (Röttger and Honig, 2011). The RAD7 monitors were compared to the reference instrument of the PTB for the concentration range of $0-4300 \mathrm{~Bq} \mathrm{~m}^{-3}$.

\subsubsection{Side-by-side measurements}

Side-by-side (sbs) measurements were performed for sixteen days directly after the campaign under field conditions. The main goals were (a) investigation of systematic differences for $\mathrm{Tn}$ and $\mathrm{Rn}$ between the three RAD7 monitors (accuracy) under realistic conditions and (b) determination of the random concentration errors of the RAD7 monitors (precision). First, the RAD7 monitors were directly flushed (without tubing) with zero air for two days. These measurements were used to calculate the limit of detection (LOD) for the automated Tn and Rn system under field conditions according to the recommendations of Currie (1968). For the sbs measurements, we installed the inlets inside the well-mixed headspace of a dynamic chamber system (volume $0.041 \mathrm{~m}^{3}$ ) (Pape et al., 2009) with an adjustable purging rate of ambient air (0-70 $\left.\mathrm{L} \mathrm{min}^{-1}\right)$. Two fans guaranteed well-mixed conditions in the chamber. The bottom of the chamber was closed and two bowls with dried soil from the experimental site were placed inside the chamber, serving as the Tn and Rn source (Fig. 2d). In order to dilute the emitted Tn and $\mathrm{Rn}$ with ambient air, the chamber purge was adjusted to different flow rates for several days, these were $70 \mathrm{~L} \mathrm{~min}^{-1}$, $35 \mathrm{~L} \mathrm{~min}^{-1}$ and $5 \mathrm{~L} \mathrm{~min}^{-1}$ for three, four and seven days, respectively. In contrast to other trace gases, such as $\mathrm{O}_{3}$ and
$\mathrm{CO}_{2}$, the fast decay of Tn can cause significant concentration differences even at small horizontal distances of only $15 \mathrm{~cm}$ at any time of the day. The application of the wellmixed dynamic chamber allowed the performance of reliable sbs measurements under field conditions, minimizing the effect of horizontal inlet separation.

\subsection{Determination of systematic and random concentration errors}

The systematic difference between the RAD7 monitors was determined by plotting the concentrations from the sbs measurements against each other and performing a bivariate weighted linear least-squares fitting regression analysis with the Williamson-York method provided in a Microsoft Excel spread sheet by Cantrell (2008). The counting statistics of the RAD7 monitors provided the weighting errors. The RAD7 at height $z_{1}$ was defined as the reference instrument, and the slope and intercept of the regressions were used to correct for the systematic error. The remaining scatter around the $1: 1$ line is the random error of the concentration difference of two RAD7 monitors ( $\sigma \Delta C$ ) (see Wolff et al., 2010). This error was found to increase with concentration (see below). To quantify the concentration dependence of $\sigma \Delta C$, we plotted the residuals of the corrected fit, binned them, calculated the means and standard deviations of each bin, and made a linear regression (see Wolff et al., 2010). The resulting regression (slope + intercept) was used to calculate $\sigma \Delta C$ as a function of the $\mathrm{Tn}$ and $\mathrm{Rn}$ concentration. This random error $\sigma \Delta C$ was calculated for the three RAD7s in all six possible combinations by exchanging $\mathrm{x}$ - and $\mathrm{y}$-axis. Since the air samples at the three heights were measured with RAD7 monitors of identical age and specifications, we assume the random 
error of each instrument to be the same $\left(\sigma C_{1}=\sigma C_{2}\right)$. Thus, we calculated an average of $\sigma \Delta C$ for all monitors and computed $\sigma C$ of one concentration measurement required for the error propagation (see below) as

$$
\begin{aligned}
& (\sigma \Delta C)^{2}=\sigma C_{1}^{2}+\sigma C_{2}^{2} \\
& \sigma C=\frac{\sigma \Delta C}{\sqrt{2}} .
\end{aligned}
$$

\subsection{Determination of transport time uncertainties}

A measured Tn profile contains information about the average transport time of air molecules between two measurement heights, $z_{1}$ and $z_{\mathrm{u}}$, for the used integration interval. If the difference of the ambient $\mathrm{Tn}$ concentrations measured at $z_{1}$ and $z_{\mathrm{u}}$ can be resolved, the average transport time (s) can be calculated according to Eq. (1). The application of this method is limited by the prevailing ambient Tn concentrations, transport and dilution by atmospheric turbulence, the instrument precision and the instrument sensitivity (LOD).

In order to estimate the uncertainty of the calculated transport times we applied the Gaussian error propagation method (e.g., Taylor, 1997; Staudt et al., 2011).

$$
\begin{aligned}
\sigma_{\tau}^{2} & =\left(\frac{\partial \tau}{\partial C_{\mathrm{Tn}_{z_{1}}}} \cdot \sigma C_{\mathrm{Tn}_{z_{1}}}\right)^{2}+\left(\frac{\partial \tau}{\partial C_{\mathrm{Tn}_{z_{\mathrm{u}}}}} \cdot \sigma C_{\mathrm{Tn}_{z_{u}}}\right)^{2} \\
& +2\left(\frac{\partial \tau}{\partial C_{\mathrm{Tn}_{z_{1}}}} \cdot \frac{\partial \tau}{\partial C_{\mathrm{Tn}_{z_{\mathrm{u}}}}} \cdot \sigma C_{\mathrm{Tn}_{z_{1}}} \cdot \sigma C_{\mathrm{Tn}_{z_{\mathrm{u}}}} \cdot r\left(C_{\mathrm{Tn}_{\mathrm{z}_{1}}}, C_{\mathrm{Tn}_{\mathrm{z}_{\mathrm{u}}}}\right)\right),
\end{aligned}
$$

where $\sigma C_{\mathrm{Tn}_{z_{1}}}$ and $\sigma C_{\mathrm{Tn}_{z_{\mathrm{u}}}}$ are the respective concentration errors (see Sect. 2.5), and $r_{\left(C_{\operatorname{Tn}_{z_{1}}}, C_{\operatorname{Tn}_{z_{\mathrm{u}}}}\right)}$ is the correlation coefficient of the measured $\mathrm{Tn}$ concentrations. Term $\mathrm{C}$ is included since the measured Tn concentrations are dependent on each other. We calculated $r_{\left(C_{\mathrm{Tn}_{\mathrm{z}}}, C_{\mathrm{Tn}_{\mathrm{z}_{\mathrm{u}}}}\right)}$ independently for daytime and nighttime as well as for periods with different inlet arrangements (see Sect. 2.3, Fig. 3).

\section{Results}

\subsection{System characterization}

\subsubsection{Tn recovery}

The pressures from $\mathrm{p} 2$ to $\mathrm{p} 5$ were found to be linearly related for the different filter clogging states (Fig. 4). This enabled us to calculate the pressure at the positions $\mathrm{p} 1-\mathrm{p} 6$ of the system using the reading of the permanently installed pressure sensor at $\mathrm{p} 3$ in each sample line (position see Fig. 1).

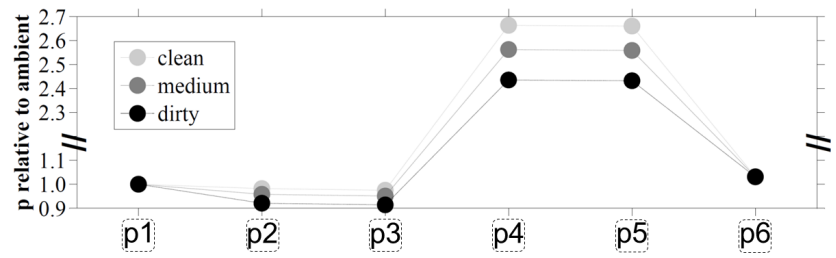

Fig. 4. Pressures measured at positions p1-p6 within the automated $\mathrm{Tn}$ and $\mathrm{Rn}$ profile system ( $\mathrm{p} 1=$ ambient pressure) during the filter clogging simulation (clean, medium, dirty).

The calculated corresponding residence times from the filter clogging experiment were $10.7 \mathrm{~s}, 10.4 \mathrm{~s}$ and $10.1 \mathrm{~s}$ for the clean, medium and dirty state, respectively (Fig. 5). For comparison, the in situ measured residence time (maximum of the $\mathrm{CO}_{2}$ peak) was $11.0 \mathrm{~s}$ (Fig. 5). In our experiment (regular filter exchange) the median residence time for each measurement level calculated from the actual volume flows (see Sect. 2.4.1) was $10.4 \mathrm{~s}$ (Fig. 5). The results from the filter clogging simulation in the laboratory compare well with the residence times under field conditions. The results imply that nearly $88 \%$ of the Tn concentration at the inlet was recovered inside the measurement system (Fig. 5). If we consider the most extreme residence times during the campaign, the maximal potential $\mathrm{Tn}$ difference between the measurement levels was only $0.8 \%$. Consequently, the Tn concentration differences due to filter clogging were neglected in the further data evaluation.

\subsubsection{Tn sensitivity}

The verification of the sensitivity in the PTB facility revealed that the predefined $\mathrm{Tn}$ sensitivity from the manufacturer was very accurate. The sensitivity of the three RAD7 showed a deviation from the reference of less than $8 \%$ within the concentration range of $0 \mathrm{~Bq} \mathrm{~m}^{-3}$ to $4300 \mathrm{~Bq} \mathrm{~m}^{-3}$.

\subsubsection{Side-by-side measurements}

The regulation of the purging rate in the dynamic chamber allowed us to vary the Tn concentration in the chamber (Fig. 6) to obtain a realistic Tn concentration range $(0-$ $300 \mathrm{~Bq} \mathrm{~m}^{-3}$ ). The highest $\mathrm{Tn}$ concentrations were measured with the lowest purging rate. The scatter of the Tn measurements increased with concentration. In contrast, the Rn concentrations could not be adjusted well using the chamber purging rate. Nevertheless, during stable nighttime situations elevated $\mathrm{Rn}$ concentrations were recorded. The dissimilarity in the feasibility of the Tn and Rn concentration adjustment by the chamber purge could be attributed to (a) the much smaller Rn emission from the soil at our site compared to Tn (see Sect. 3.3) and (b) the likelihood for an alpha decay of a soil emitted Tn or Rn nuclide to happen within the dynamic chamber volume. For the three flushing rates, $33 \%$, 


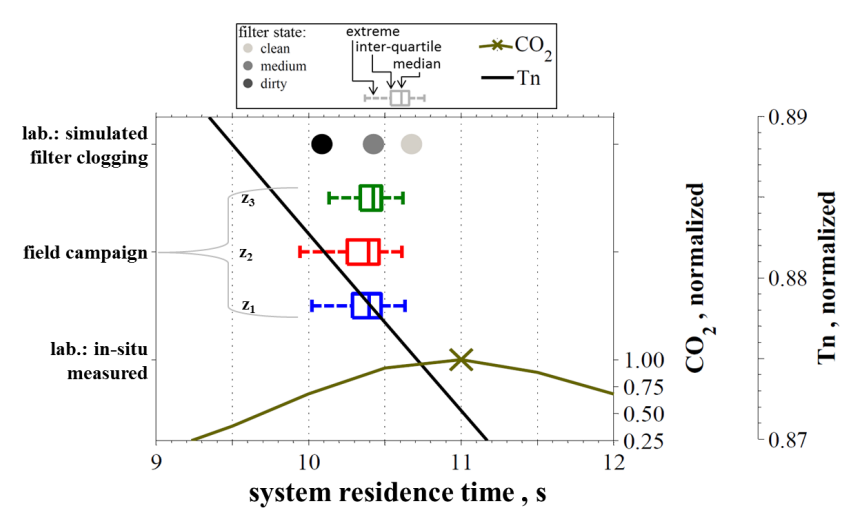

Fig. 5. Comparison of (i) calculated residence times from the simulated filter clogging experiment in the laboratory (filled circles), (ii) residence times determined from the field data set $\left(z_{1}-z_{3}\right.$ with median, interquartile range and extreme values) and (iii) in situ measured residence times $\left(\mathrm{CO}_{2}\right.$ experiment, green line) with (iv) the resulting radioactive $\mathrm{Tn}$ decay (black line) calculated from Eq. (1).

$52 \%$ and $92 \%$ of the soil emitted $\mathrm{Tn}$ isotopes decayed inside the dynamic chamber volume, whereas for $\mathrm{Rn}$ the much longer $T_{0.5}$ caused only $<0.04 \%$ of the isotopes to decay within the chamber.

\subsubsection{Limit of detection}

The LOD for $\mathrm{Tn}\left(\mathrm{LOD}_{\mathrm{Tn}}\right)$ determined under field conditions with a 60 min integration time when purging the instruments with zero air during the sbs measurement varied by $\pm 20 \%$ for the different RAD7 monitors. In contrast, the LOD $_{\mathrm{Rn}}$ was comparable for all RAD7s (Table 2). The determined $\mathrm{LOD}_{\mathrm{Tn}}$ of $18.3 \mathrm{~Bq} \mathrm{~m}^{-3}$ for an integration time of $60 \mathrm{~min}$ was three times higher than that of $\mathrm{Rn}$.

\subsection{Systematic and random errors}

Figure 7 shows an example for the determination of the systematic and random errors. The averaged random errors of $\sigma \Delta C$ for $\mathrm{Tn}$ and $\mathrm{Rn}$ were $\sigma \Delta C_{\mathrm{Tn}}=0.10 C+$ 13.2 $\mathrm{Bq} \mathrm{m}^{-3}$ and $\sigma \Delta C_{\mathrm{Rn}}=0.19 C+9.5 \mathrm{~Bq} \mathrm{~m}^{-3}$, respectively. Hence, the averaged random concentration errors $\sigma C$ (Eq. 3) for $\mathrm{Tn}$ and $\mathrm{Rn}$ used for the Gaussian error propagation to estimate $\sigma_{\tau}$ were $\sigma C_{\mathrm{Tn}}=\frac{0.10 C+13.2 \mathrm{~Bq} \mathrm{~m}-3}{\sqrt{2}}$ and $\sigma C_{\mathrm{Rn}}=\frac{0.19 C+9.5 \mathrm{~Bq} \mathrm{~m}^{-3}}{\sqrt{2}}$. Consequently, the Tn and $\mathrm{Rn}$ concentrations where $\sigma C / C=1$ were $10.0 \mathrm{~Bq} \mathrm{~m}^{-3}$ and $7.8 \mathrm{~Bq} \mathrm{~m}^{-3}$, respectively. The obtained median precisions for three concentration classes $\left(>100 \mathrm{~Bq} \mathrm{~m}^{-3}, 100-15 \mathrm{~Bq} \mathrm{~m}^{-3}\right.$, $<15 \mathrm{~Bq} \mathrm{~m}^{-3}$ ) were $8.8 \%, 23.2 \%$ and $132.1 \%$ for Tn and $16.6 \%, 25.0 \%$ and $99.2 \%$ for $\mathrm{Rn}$, respectively.

\subsection{Radon and thoron concentration profiles}

The soil at our measurement site is a much stronger source for $\mathrm{Tn}$ than for $\mathrm{Rn}$ (median of $C_{\mathrm{Rn}} / C_{\mathrm{Tn}}=0.07$ at $z_{1}=$

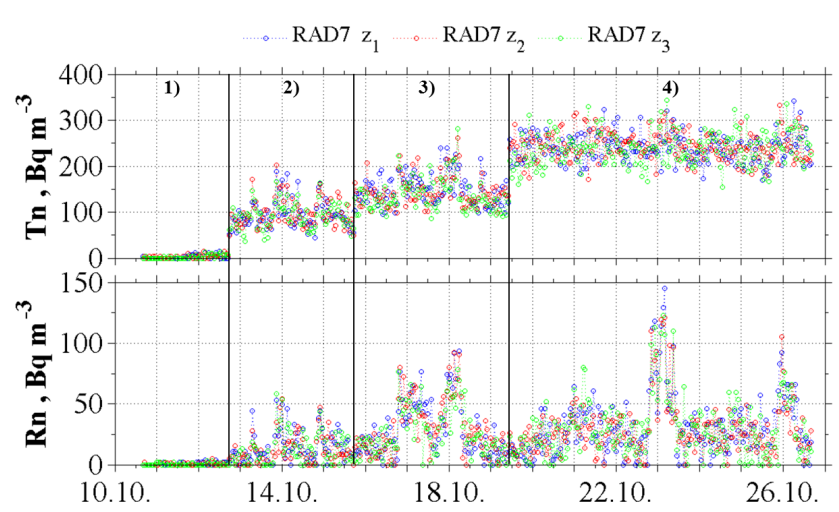

Fig. 6. Time series of $\mathrm{Tn}$ and $\mathrm{Rn}$ concentrations during sixteen days of side-by-side measurements (10-26 October 2011) measured with the RAD7 monitors ( 60 min integration time). After the zero air measurement (1) we purged the chamber with $70 \mathrm{~L} \mathrm{~min}^{-1}$ (2), $35 \mathrm{Lmin}^{-1}$ (3), and $5 \mathrm{Lmin}^{-1}$ (4).

$0.04 \mathrm{~m})$. To explain our results, we have selected $\mathrm{Tn}$ and Rn concentration measurements of two days in block 2 (period 1) and two days in block 3 (period 2) (Fig. 8a-d) with the respective inlet height arrangements (see Sect. 2.3, Fig. 3). Typical diurnal cycles with higher wind speeds during daytime and lower at nighttime were prevailing during both periods (Fig. 8e-f). The diurnal courses of measured Tn and Rn concentrations mirror the variation of the wind speed, with higher Tn and Rn concentrations during nighttime than during daytime. This is a typical pattern since stable stratification in the air layer above the canopy top is known to inhibit vertical exchange during nighttime, while during daytime the vertical exchange is driven by turbulent mixing. Our temperature profile measurements (not presented) reveal that the transition from stable to unstable conditions took place after sunrise at around 06:00 LT (CET), and the transition from unstable to stable conditions some hours before sunset (20:00 LT) at around 16:00 to 17:00 LT. Tn concentrations ranged from 0 to $830 \mathrm{~Bq} \mathrm{~m}^{-3}$ and $\mathrm{Rn}$ concentrations ranged from 0 to $250 \mathrm{~Bq} \mathrm{~m}^{-3}$, both with highest concentrations close to the ground.

A pronounced vertical Tn profile was measured during period 1 (Fig. 8a). The measured Tn concentration differences between $z_{1}$ and $z_{3}$ were about $400 \mathrm{~Bq} \mathrm{~m}^{-3}$ during midnight and about $130 \mathrm{~Bq} \mathrm{~m}^{-3}$ in the early afternoon. These values were typical for period 1 and the precision of the RAD7 monitors was sufficient to resolve significant vertical concentration differences. Obviously, this inlet height arrangement was optimal to determine vertical Tn concentration differences.

In contrast, we found that the inlet arrangement of period 1 was not suitable to measure significant vertical Rn concentration differences between all three heights (Fig. 8c). In particular, the daytime Rn concentrations at $z_{2}$ and $z_{3}$ were often within the random concentration error (see Sect. 3.2) and the scatter of the concentrations further complicates the determination of significant $\mathrm{Rn}$ differences. 

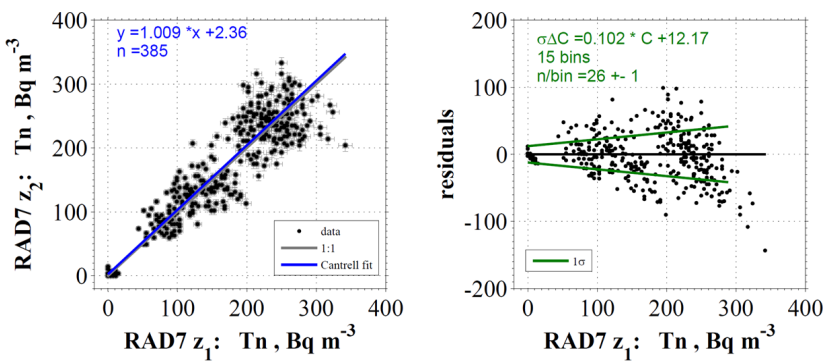

Fig. 7. Example of systematic and random error determination from side-by-side measurements. Left panel: determination of the systematic error of the Tn concentration between the RAD7 at $z_{1}$ and $z_{2}$ using the bivariate weighted linear least-squares fitting regression analysis by the Williamson-York method (Cantrell, 2008). Error bars represent the uncertainties from counting statistics of the RAD7 $(\sigma=\sqrt{n})$. Right panel: quantification of the random error $(\sigma \Delta C)$ from the residuals around the fit (for details see Sect. 2.5 and Wolff et al., 2010).

Table 2. Limit of detection (LOD in $\mathrm{Bq}^{-3}$ ) of the RAD7 monitors (with the system characteristics described in Sect. 2.2) determined under field conditions during the zero air measurements.

\begin{tabular}{lrrrr}
\hline RAD7 & LOD $_{\mathrm{Tn}}$ & mean LOD & LOD $_{\mathrm{Rn}}$ & mean LOD \\
\hline$z_{1}$ & 18.1 & & 5.8 & \\
$z_{2}$ & 22.0 & 18.3 & 6.4 & 6.2 \\
$z_{3}$ & 14.7 & & 6.4 & \\
\hline
\end{tabular}

After increasing the inlet separation distance (period 2), the Tn concentration differences between $z_{1}$ and $z_{2}$ (Fig. 8b) are still significantly different from each other. The concentrations at $z_{1}$ and $z_{2}$ range from daytime values of $100 \mathrm{~Bq} \mathrm{~m}^{-3}$ and $\sim 20 \mathrm{~Bq} \mathrm{~m}^{-3}$, respectively, to nighttime values of $600 \mathrm{~Bq} \mathrm{~m}^{-3}$ and $100-300 \mathrm{~Bq} \mathrm{~m}^{-3}$, respectively. However, the Tn concentrations measured at $z_{3}=80 \mathrm{~cm}$ are always below $30 \mathrm{~Bq} \mathrm{~m}^{-3}$ during period 2 and may occasionally reach the $\mathrm{LOD}_{\mathrm{Tn}}$.

The Rn nighttime profile (Fig. 8d) shows substantially higher concentration differences $\left(25-250 \mathrm{~Bq} \mathrm{~m}^{-3}\right)$ than during period 1. With this inlet arrangement the precision of the RAD7 monitors was sufficient to resolve significant vertical $\mathrm{Rn}$ concentration differences during nighttime.

\subsection{Calculation of transport times and quality assurance}

Since the subject of this paper is the description and evaluation of the novel automated measurement system, we will mainly focus on the data quality, rather than describe and interpret diurnal courses of the transport times. Transport times $\tau$ were calculated using the measured Tn concentrations (Fig. 8a, b) using Eq. (1). The propagation of previously determined random concentration errors $(\sigma C)$ enabled us to assign each value of $\tau$ with an absolute uncertainty $\left(\sigma_{\tau}\right)$
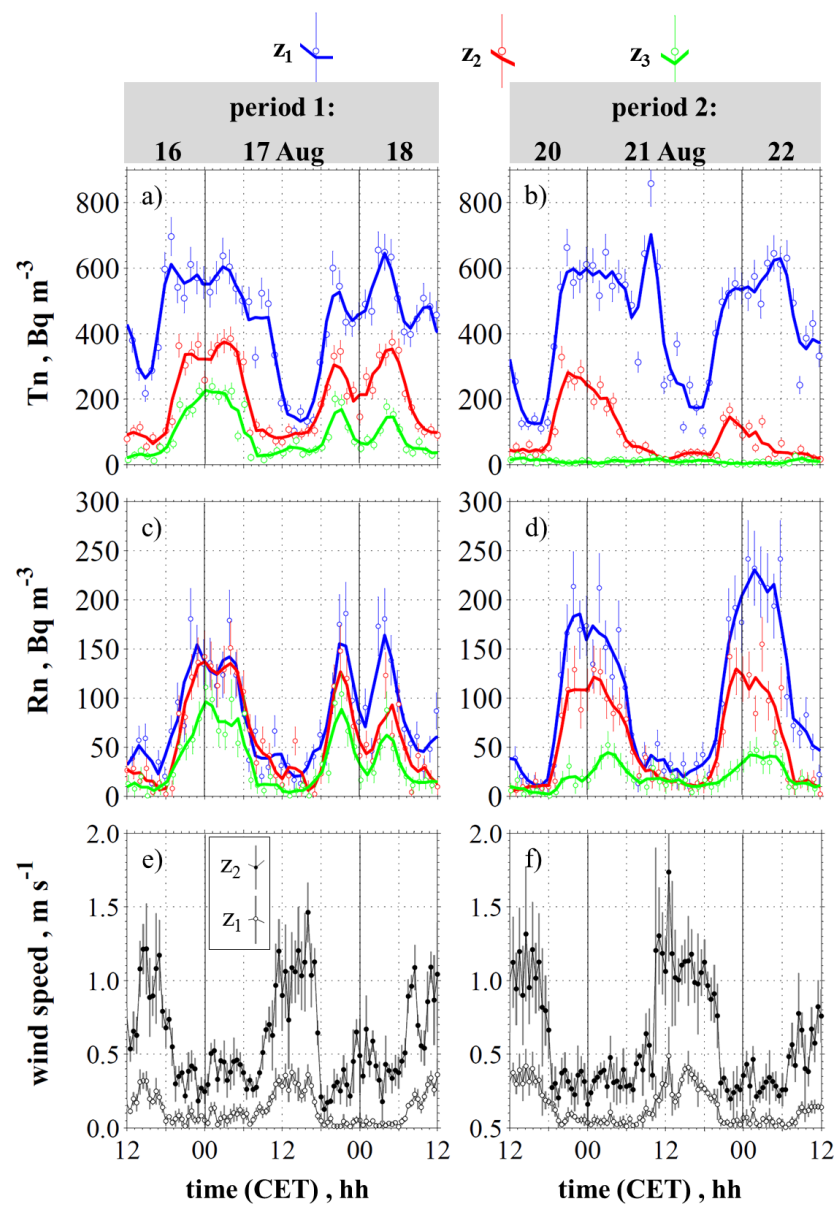

Fig. 8. Tn and $\mathrm{Rn}$ concentrations as well as wind speeds $\left(z_{1}=\right.$ $0.2 \mathrm{~m}, z_{2}=0.8 \mathrm{~m}$ ) measured during two periods with different inlet height arrangements (period 1: 16-18 August, period 2: 20-22 August, see Fig. 3). Dots with error bars in plots (a-d) represent the RAD7 concentration readings (integration time $60 \mathrm{~min}$ ) and the corresponding random errors $(\sigma C)$. The solid lines show the running means (width: $3 \mathrm{~h}$ ) of the concentrations. In plots (e) and (f) $30 \mathrm{~min}$ averages of the measured wind speed are shown, where error bars represent standard deviations.

(see Eq. 4). We assessed the data quality of $\tau$ using a classification according to the magnitude of the relative uncertainty. Three data quality classes were introduced $\left(\frac{\sigma_{\tau}}{\tau}<0.5\right.$ : good; $0.5 \leq \frac{\sigma_{\tau}}{\tau}<1$ : adequate; $\frac{\sigma_{\tau}}{\tau} \geq 1$ : inadequate quality).

The calculated transport times for the two investigated periods are shown in Fig. 9. Our setup allowed the calculation of $\tau$ for three layers within the canopy. The lower layer was between $z_{1}$ and $z_{2}$ (Fig. 9a, b), the upper layer between $z_{2}$ and $z_{3}$ (Fig. 9c, d) and the overall transport time between $z_{1}$ and $z_{3}$ (Fig. 9e, f). Due to the varying inlet height arrangements in periods 1 and 2, the lower and upper layers were not identical. However, the overall transport time during period 1 (Fig. 9e) corresponds to the one of the lower layer in period 2 (Fig. 9b), representing the transport between $0.04 \mathrm{~m}$ and $0.20 \mathrm{~m}$. 


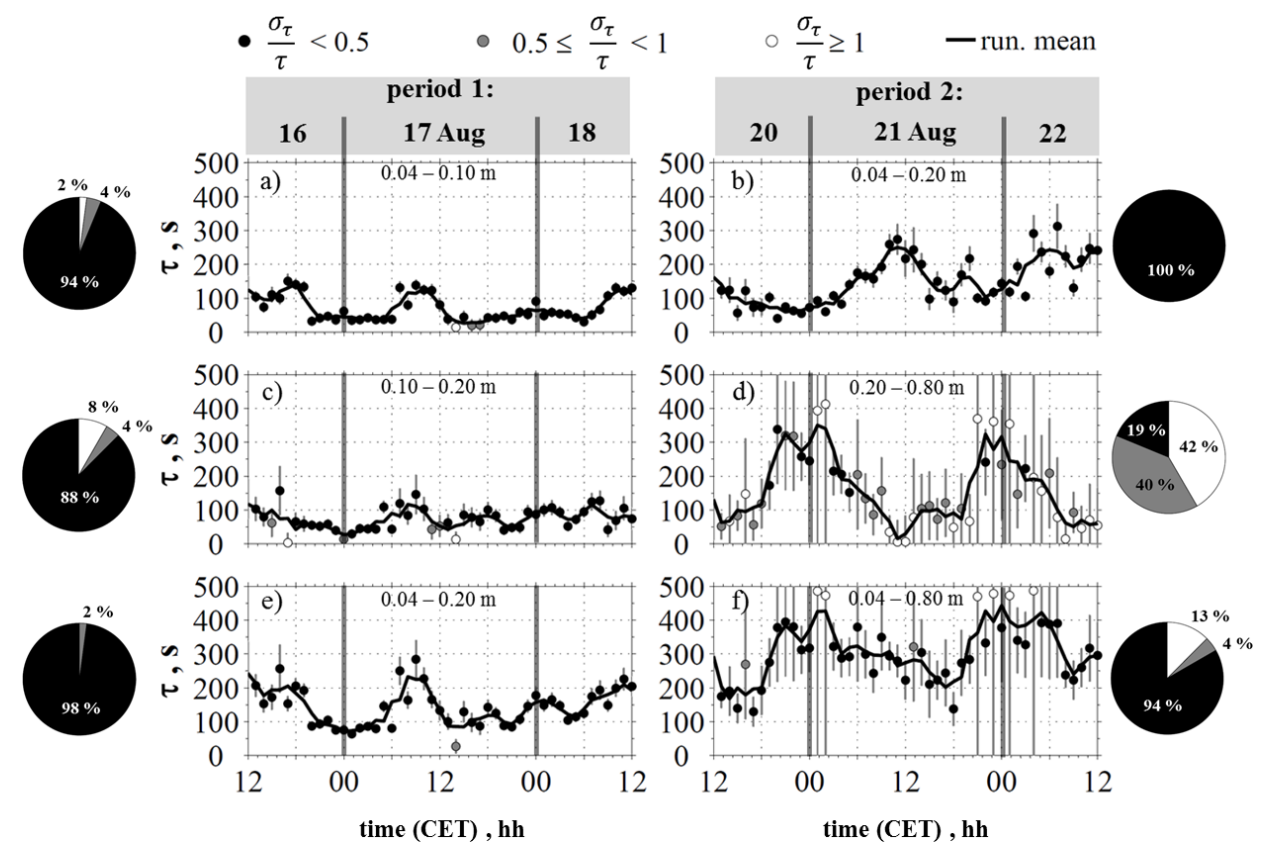

Fig. 9. Calculated transport times, $\tau$, for three layers (lower $\mathbf{a}, \mathbf{b}$; upper $\mathbf{c}, \mathbf{d}$; and overall $\mathbf{e}, \mathbf{f}$ ) classified according to the magnitude of the relative uncertainty for the two selected periods. The error bars represent the absolute uncertainty of $\tau$ determined using Gaussian error propagation (Eq. 4). The pie diagrams represent the percentage of $\tau$ in each quality class for the plots shown (black: good, grey: adequate, white: inadequate quality).

During period 1, with its more compact inlet arrangement closer to the ground, both $\tau$ in the lower and in the upper layer ranged between $20 \mathrm{~s}$ and $150 \mathrm{~s}$ (Fig. 9a, c). The overall transport time of period 1 (Fig. 9e) corresponds to the sum of both other layers and indeed featured a similar diurnal pattern as in the lower layer during period 2 (Fig. 9b). These values were highest from around 06:00 to 12:00 LT, ranging from $200 \mathrm{~s}$ to $300 \mathrm{~s}$, and were lower during nighttime (50-150 s). The diurnal course of $\tau$ in the upper and lower layer during period 2 were rather different from each other (Fig. 9b, d). In the lower layer, $\tau$ ranged from nighttime minima of $100 \mathrm{~s}$ to midday maxima of about $300 \mathrm{~s}$. In contrast, the $\tau$ values in the upper layer featured maxima during nighttime of up to $350 \mathrm{~s}$ and daytime minima ranging from $10 \mathrm{~s}$ to $120 \mathrm{~s}$. The overall transport time during period 2 (Fig. 9f) shows the largest values always above $120 \mathrm{~s}$, with maxima occasionally exceeding $400 \mathrm{~s}$, which is attributed to the large layer thickness of $0.76 \mathrm{~m}$.

The transport times calculated for period 1 generally show better data quality than those for period 2 (pie diagrams in Fig. 9). For period 1, 94\%, $88 \%$ and $98 \%$ of the calculated $\tau$ values for the lower, upper and overall layer, respectively, are of good data quality. During period 2 the lower and overall layer show comparably good data quality with $100 \%$ and $94 \%$ of the $\tau$ values with good quality, whereas $40 \%$ and $42 \%$ of the $\tau$ values in the upper layer are of adequate and inadequate data quality, respectively.
Calculated $\tau$ values belonging to the inadequate data quality class can be found at any time of the day and stand in many cases out of the general diurnal course (often as extreme values) in the corresponding plots (e.g., Fig. 9c, d and $f$.

\section{Discussion}

\subsection{System performance}

The presented system for the continuous determination of transport times near the ground is based on vertical Tn profile measurements at three heights using three RAD7 monitors that are selective for $\mathrm{Tn}$ and $\mathrm{Rn}$. Although other examples for automated Tn profile measurements can be found in the literature (e.g., Lehmann et al., 1999; Nemitz et al., 2009; Gut et al., 2002; Hens, 2009), the major drawback of these studies is the application of a pair of non-selective monitors to measure a sequentially switched profile. Thus, the measured vertical concentration differences are prone to non-stationarities, particularly for longer integration times. While their method minimizes systematic errors between the measurement heights, the random error of the Tn concentration can be amplified since it is determined from the difference of two signals of non-selective monitors (for details see Lehmann et al., 1999). In contrast, the system of Butterweck et al. (1994), who operated a simultaneous profile consisting of four instruments that are selective for Tn and 
$\mathrm{Rn}$, is not prone to non-stationarities. Nevertheless, none of the previous studies assessed systematic or random errors of the determined Tn concentration profiles and the calculated $\tau$ values. Such an analysis is crucial for applications with multiple analyzers and required for a thorough interpretation of the in-canopy transport.

The overall performance of the novel automated measurement system was satisfying, with a Tn recovery of $88 \%$ that was relatively stable and comparable for all sampling lines. Our setup comprising PFA tubing, pumps, Nafion tubing and MFCs strongly modified the standard setup of the RAD7 monitors. The performance of the Nafion dryers was excellent with an average RH of $4 \%$ in all RAD7 throughout the field experiment.

We found that the signal of the RAD7 at low concentrations is quite noisy. The higher LOD for Tn $\left(18.3 \mathrm{~Bq} \mathrm{~m}^{-3}\right)$ than for Rn was largely caused by the lower sensitivity of the RAD7 for Tn. The $\mathrm{LOD}_{\mathrm{Tn}}$ for the setup used, e.g., in Lehmann et al. (1999) is not mentioned. Since they determine $\mathrm{Tn}$ as the sum of two AlphaGuard signals, we assume that the $\mathrm{LOD}_{\mathrm{Tn}}$ also exceeded $\mathrm{LOD}_{\mathrm{Rn}}$ for their setup.

The determined mean $\mathrm{LOD}_{\mathrm{Rn}}$ of $6.2 \mathrm{~Bq} \mathrm{~m}^{-3}$ (see Table 2) is high compared to that of Wada et al. (2010), who developed an electrostatic $\mathrm{Rn}$ system with an $\mathrm{LOD}_{\mathrm{Rn}}$ between 0.16 and $0.2 \mathrm{~Bq} \mathrm{~m}^{-3}$ for $60 \mathrm{~min}$ integration time. They achieved this by operating it at a flow rate of $3 \mathrm{~L} \mathrm{~min}^{-1}$ and by using much larger measurement chambers of $32 \mathrm{~L}$ and $16.8 \mathrm{~L}$ volume, respectively. In contrast, the $\mathrm{LOD}_{\mathrm{Rn}}$ of the AlphaGuard operated at 10 min integration time, as used in the studies of Lehmann et al. (1999), Nemitz et al. (2009) and Hens (2009), was determined to be $12 \mathrm{~Bq} \mathrm{~m}^{-3}$ by Hens (2009) and therefore twice as high as for the RAD7. The LOD comparison with the system used by Butterweck et al. (1994) was not possible due a lack of information on their system configuration.

The systematic error of the RAD7 for Tn determined in the PTB of $6 \%$ to $8 \%$ was somewhat higher than the results from the sbs measurements, which were in the order of $1 \%$ to $3 \%$ (cf. Fig. 7). Since $75 \%$ of all measured Tn concentrations during the campaign were below $255 \mathrm{~Bq} \mathrm{~m}^{-3}$, we consider the sbs result as representative for the systematic error of the Tn measurements. The manufacturer provided an Rn error of $2 \%$ on the calibration certificates. The application of the bivariate regression analysis on the sbs data resulted in a systematic error for $\mathrm{Rn}$ in the range of $1 \%$ to $6 \%$, which was corrected for.

The field measurements were conducted under partly harsh field conditions including changing temperatures and RHs for an extended period of two months, which is quite different to standard applications of the RAD7. The monitors proved to be suitable under all conditions at our field site to resolve vertical concentrations differences of $\mathrm{Tn}$ and also those of Rn under stable nighttime conditions. These findings, in combination with the comparably low price and the Tn and Rn selectivity of the RAD7, may be convincing arguments for equipping a profile system with these monitors. However, it has to be kept in mind that the analyzer precision is not sufficient for the low Tn and Rn concentrations found at the surface at many sites, and at heights exceeding a few meters above the surface at all sites.

\subsection{Comparison of transport times with existing empirical parameterizations}

A comparison of our transport times with those of Lehmann et al. (1999) and Nemitz et al. (2009) revealed reasonable agreement for the lowest layer $(0.04-0.2 \mathrm{~m})$, although the canopy structure was probably quite different for all study sites. In addition, we compared our measured and quality controlled transport times with currently existing parameterizations that are used in models such as SURFATM (see Personne et al., 2009). The transport time is expressed as the total resistance multiplied with the layer thickness $(h)$.

$\tau(\operatorname{surfatm})=\left(R_{\mathrm{ac}}+R_{\mathrm{a}}\left(z_{\mathrm{ref}}\right)\right) \cdot h$,

where $R_{\mathrm{ac}}$ is the in-canopy resistance and $R_{\mathrm{a}}$ the aerodynamic resistance (Thom, 1975) at the reference height $\left(z_{\text {ref }}=0.8 \mathrm{~m}\right)$. We calculated $\tau$ (surfatm) for our overall layer $\left(z_{1}-z_{3}\right)$ and for data from block 3 according to Personne et al. (2009) (equations modified):

$$
\begin{aligned}
R_{\mathrm{ac}}=\frac{h_{\mathrm{c}} \cdot \exp \left(\alpha_{u}\right)}{\alpha_{u} \cdot K_{m}\left(h_{\mathrm{c}}\right)} \cdot\left\{\exp \left(\frac{-\alpha_{u} \cdot z_{0 \mathrm{~s}}}{h_{\mathrm{c}}}\right)-\exp \left(\frac{\alpha_{u} \cdot\left(d+z_{0}\right)}{h_{\mathrm{c}}}\right)\right\} \\
R_{\mathrm{a}}\left(z_{\text {ref }}\right)=\frac{1}{\kappa^{2} \cdot u\left(z_{\text {ref }}\right)} \cdot\left\{\ln \left[\frac{Z}{z_{0}}\right]-\Psi_{\mathrm{H}}(Z / L)\right\} \\
\cdot\left\{\ln \left[\frac{Z}{z_{0}}\right]-\Psi_{\mathrm{M}}(Z / L)\right\},
\end{aligned}
$$

where $h_{\mathrm{c}}$ is the canopy height, $\alpha_{u}(=4.2)$ the attenuation coefficient for the decrease of the wind speed inside the plant cover, $z_{0 \mathrm{~s}}$ the ground surface roughness length, $d$ the displacement height, $z_{0}$ the canopy roughness height, $K_{m}\left(h_{\mathrm{c}}\right)$ the eddy diffusivity coefficient at $h_{\mathrm{c}}\left(K_{m}=\kappa \cdot u_{*} \cdot\left(h_{\mathrm{c}}-d\right)\right)$, $\kappa$ the von Kàrmàn constant, $u\left(z_{\text {ref }}\right)$ the horizontal wind speed at $z_{\text {ref }}, Z=z_{\text {ref }}-d, L$ the Monin-Obukhov length and $\Psi_{\mathrm{H}}$ and $\Psi_{\mathrm{M}}$ are the stability correction functions for heat and momentum, respectively. Furthermore, we compared our transport times with an empirical approach provided by van Pul and Jacobs (1994) used, e.g., in the STOCHEM model (Sanderson et al., 2003), where the transport time is expressed as

$$
\tau(\operatorname{vanPul})=\left(\frac{13.9 \cdot \mathrm{LAI} \cdot h_{\mathrm{c}}^{2}}{u_{*}}\right),
$$

where LAI is the single-sided leaf area index. For our study, the LAI was 4.8 as determined by biomass harvest and photographic imagery of subsamples (harvested area: $0.29 \mathrm{~m}^{2}$ ) 


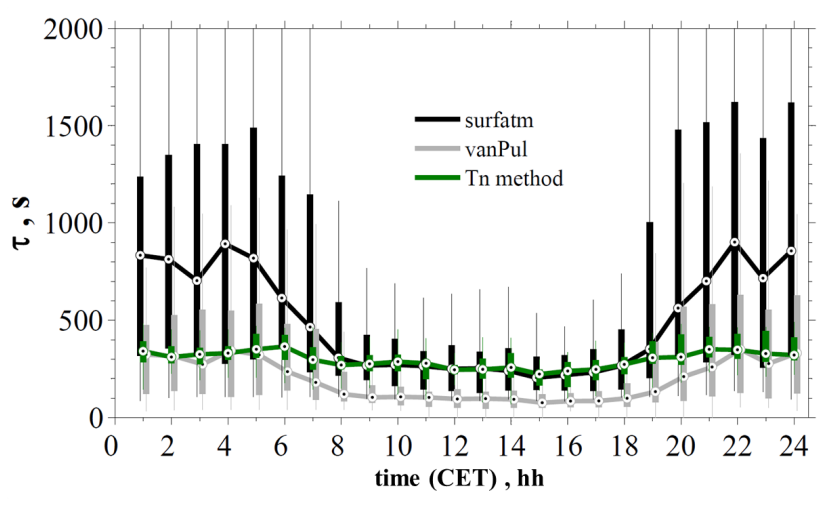

Fig. 10. Median diurnal course of measured transport times between 0.04 and $0.8 \mathrm{~m}$ using the Tn method (values of inadequate quality were rejected) compared to existing empirical parameterizations for all data from block 3 for the natural grassland site. The statistical distribution of the data sets is represented by hourly boxplots. The dots indicate the medians, the filled boxes cover the interquartile range, and the whiskers represent the extreme data points.

close to the inlets after the experiment. The values of $u_{*}, z_{0 \mathrm{~s}}$, $z_{0}, d, L, \Psi_{\mathrm{H}}, \Psi_{\mathrm{M}}$ were estimated using standard micrometeorological methods (Foken, 2008).

Measured median transport times $(\tau)$ between $z_{1}$ and $z_{3}$ for all data from block 3 range between $350 \mathrm{~s}$ during nighttime to 220-290 s during daytime (Fig. 10). The values are in very good agreement with $\tau$ (surfatm) during daytime from around 09:00 to 18:00 LT. However, nighttime values of $\tau$ (surfatm) are significantly higher than the measured $\tau$ values and range between $700 \mathrm{~s}$ and $900 \mathrm{~s}$. Although the transport in the layer just above the canopy is expressed by $R_{\mathrm{a}}$, the value of $\tau$ (surfatm) mainly depends on $R_{\mathrm{ac}}$ since the contribution of $R_{\mathrm{a}}$ is below $3 \%$ at any time of the day. This reveals that the parameterization of $R_{\mathrm{ac}}$ by Personne et al. (2009) is not suitable to accurately calculate the incanopy transport times during nighttime in this canopy. The reason for the much lower measured nighttime values of $\tau$ is the presence of unstable conditions and convective transport in the lowest part of the canopy, which was confirmed by measured temperature profiles (not shown). In contrast, $\tau$ (vanPul) compares well with the measured $\tau$ values during nighttime, but is significantly lower during daytime with values of around $100 \mathrm{~s}$. Since both parameterizations require $u_{*}$ as input, which typically features very high uncertainties during prevailing low wind speeds (mainly at nighttime), the contrasting results are remarkable. In addition, the Tn method showed a much smaller scatter than transport times derived from empirical parameterizations, as indicated by the interquartile range in Fig. 10.

\subsection{Transport time uncertainty}

Since transport times of good quality and those of inadequate quality with high uncertainties were present during our

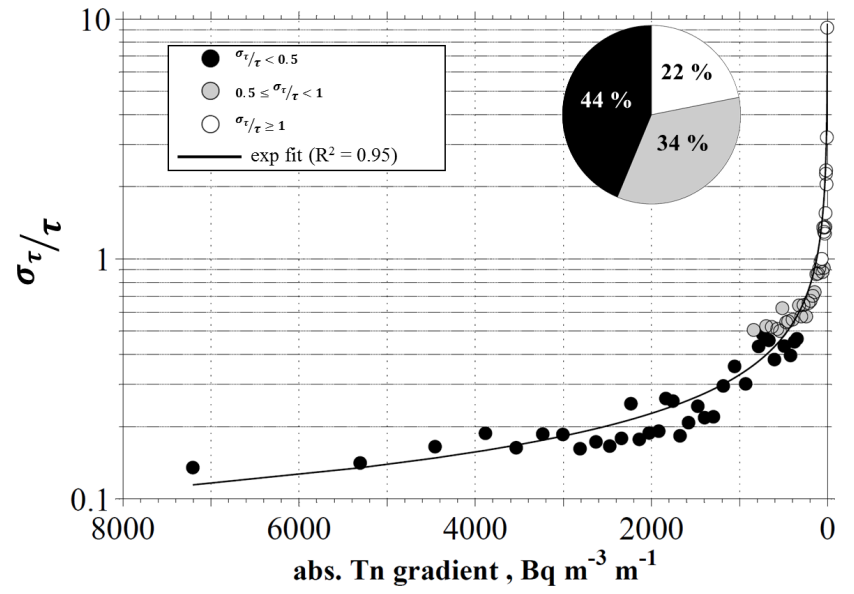

Fig. 11. Dependency of the relative uncertainty of the transport time $\left(\frac{\sigma_{\tau}}{\tau}\right)$ on the absolute Tn gradient for the entire data set (51 days), including all inlet height arrangements (block 1-3) and heights $\left(z_{1}\right.$, $z_{2}, z_{3}$ ). The data were sorted by the magnitude of the Tn gradient and averages of bins $(n=50)$ were calculated before the exponential fit was made. The pie diagram summarizes the fraction of $\tau$ values in each quality class (black: good, grey: adequate, white: inadequate quality (for details see text).

experiment, we conducted a detailed analysis to identify the inlet height arrangement with the optimal performance for the determination of transport times using the Tn method. The comparison of the $\tau$ values of inadequate quality with the measured Tn concentration profiles (Fig. 8) indicates that inadequate quality may occur when (a) the concentration differences are very small (e.g., Figs. $8 \mathrm{a}$ and $9 \mathrm{c}\left(z_{2}\right.$ and $\left.z_{3}\right)$ ), or (b) the Tn concentration at the upper of both inlet heights $\left(z_{u}\right)$ is very low (see Figs. $8 \mathrm{~b}$ and $9 \mathrm{~d}$ ).

To investigate (a), we plotted the $\sigma_{\tau}$ values as a function of the measured Tn gradient for the entire Tn profile data set (51 days) including all inlet height arrangements (block 13 ) and heights $\left(z_{1}, z_{2}, z_{3}\right)$, and found a strong exponential relationship (Fig. 11). Obviously, at high absolute gradients the uncertainty of the transport time is lowest and the uncertainty increases significantly with decreasing gradients. In order to obtain reliable values for the transport times with $\frac{\sigma_{\tau}}{\tau}<0.5$, an absolute gradient of at least $1000 \mathrm{~Bq} \mathrm{~m}^{-3} \mathrm{~m}^{-1}$ is desirable. In the intermediate $\mathrm{Tn}$ gradient range between 1000 and $350 \mathrm{~Bq} \mathrm{~m}^{-3} \mathrm{~m}^{-1}$, the values of $\frac{\sigma_{\tau}}{\tau}$ range from 0.3 to 0.6. To obtain $\tau$ values with $\frac{\sigma_{\tau}}{\tau}$ smaller than unity, the gradient should not be $<70 \mathrm{~Bq} \mathrm{~m}^{-3} \mathrm{~m}^{-1}$. Using the findings from Fig. 11 we are able to deduce a minimal Tn concentration difference that has to be measured between two inlet heights in order to determine transport times of good quality. For example, during period 1 between $z_{1}$ and $z_{2}(0.04 \mathrm{~m}$ and $0.1 \mathrm{~m}$ ) this value is $60 \mathrm{~Bq} \mathrm{~m}^{-3}$, which is prevailing at any time. Additionally, the dependency of $\frac{\sigma_{\tau}}{\tau}$ on the Tn gradient underlines the importance of a careful choice of the inlet heights. 

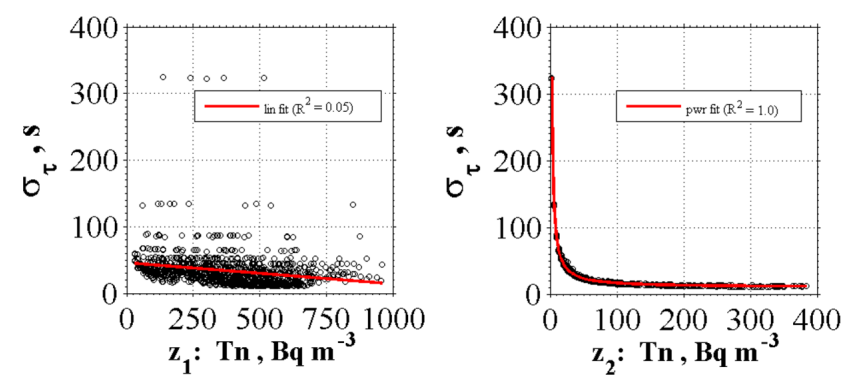

Fig. 12. Dependency of the absolute uncertainty of the transport time $\left(\sigma_{\mathrm{t}}\right)$ on the Tn concentrations measured at the lower $\left(C_{\mathrm{Tn}_{z_{1}}}\right)$ and upper $\left(C_{\mathrm{Tn}_{z \mathrm{u}}}\right)$ inlet positions using the data from $z_{1}$ (left panel) and $z_{2}$ (right panel) for the entire data set (51 days) including all inlet height arrangements (block 1-3).

Of all determined $\tau$ values (block $1-3, z_{1}, z_{2}, z_{3}$ ), $44 \%$ are of good quality (pie diagram in Fig. 11), followed by $34 \%$ and $22 \%$ in the adequate and inadequate quality class, respectively. The data quality of the $\tau$ values presented for periods 1 and 2 (pie diagrams in Fig. 9) is higher than the overall data quality, except for the upper layer during period 2 (Fig. 9d). Period 2 represents the inlet height arrangement during block 3 (Fig. 3), which is the longest of the three blocks and lowers the overall data quality mainly due to the low data quality in the upper layer. This can be explained by (b) the influence of the measured $\mathrm{Tn}$ concentration at the upper inlet height $\left(C_{\mathrm{Tn}_{\mathrm{zu}}}\right.$ in Eq. 1) on $\sigma_{\tau}$, which we compare with the effect of the Tn concentration at the lower inlet height $\left(C_{\mathrm{Tn}_{z_{1}}}\right)$ on $\sigma_{\tau}$ (shown using the values measured at $z_{2}$ and $z_{1}$; Fig. 12). While the values of $C_{\mathrm{Tn}_{z u}}$ were found to have a strong influence on the magnitude of $\sigma_{t}$ (following a power function), the values of $C_{\mathrm{Tn}_{z_{1}}}$ showed only a weak impact. Higher values of $C_{\operatorname{Tn}_{z u}}$ result in low absolute $\sigma_{\tau}$ values and lower $C_{\mathrm{Tn}_{z \mathrm{u}}}$ values cause a substantial increase of $\sigma_{\tau}$. Since the soil is the Tn source and $z_{\mathrm{u}}$ is located at a higher distance from the ground than $z_{1}$, lower Tn concentrations are expected to be measured at $z_{\mathrm{u}}$. This fact automatically increases the probability that $C_{\mathrm{Tn}_{z \mathrm{u}}}$ is close to or below the LOD, where the relative value of $\sigma C_{\mathrm{Tn}_{z u}}$ can be close to or even higher than unity. Since $\sigma C_{\mathrm{Tn}_{z u}}$ is propagated it may cause very high values of $\sigma_{\tau}$. Furthermore, $C_{\mathrm{Tn}_{z \mathrm{u}}}$ is the denominator in Eq. (1) and thus strongly impacts $\tau$. Consequently, a more compact vertical inlet height arrangement will provide more reliable $\tau$ values. The vertical limit of the inlet height separation for our system at any site can be assessed by applying the results in Fig. 11 .

\subsection{Contribution of individual error propagation terms}

We additionally quantified the contribution of the individual error propagation terms A, B and C (Eq. 4) to the total transport time uncertainty $\sigma_{\mathrm{t}}$. Note that the sum of error terms A and B can be reduced by term C (cf. Eq. 4). Figure 13 presents the error partitioning as a function of

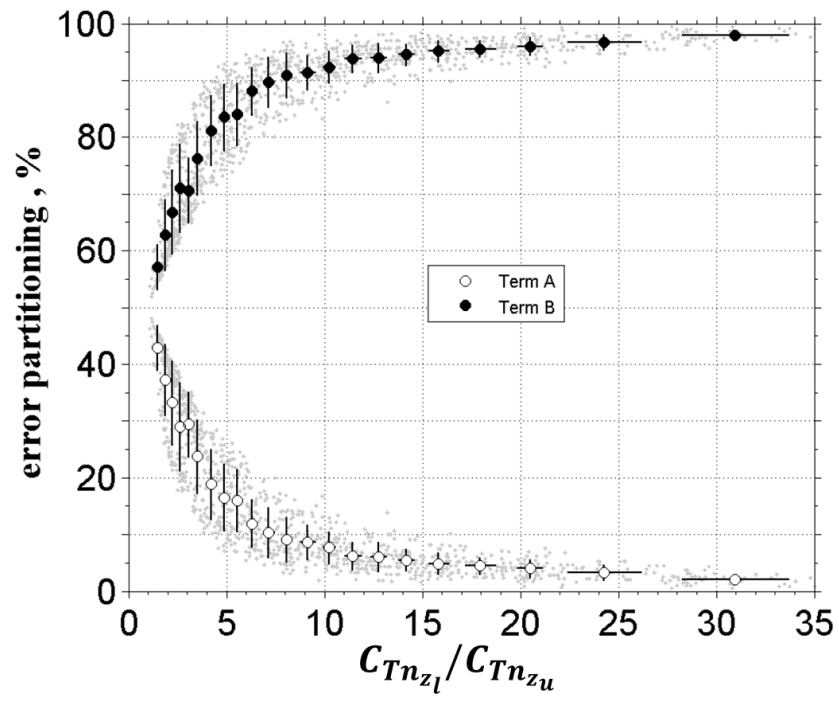

Fig. 13. The error partitioning of term $A$ and $B$ in Eq. (4) as a function of the $C_{\operatorname{Tn}_{z_{1}}} / C_{\mathrm{Tn}_{z_{\mathrm{u}}}}$ ratio for the entire data set (51 days) including all inlet height arrangements (block 1-3) and heights $\left(z_{1}\right.$, $\left.z_{2}, z_{3}\right)$.

the $C_{\operatorname{Tn}_{z_{1}}} / C_{\mathrm{Tn}_{\mathrm{zu}}}$ ratio for our entire Tn data set. Generally, terms A and B contribute with up to $50 \%$ and $50-100 \%$ to the overall uncertainty $\sigma_{\mathrm{t}}$, respectively. This highlights the strong impact of $C_{\mathrm{Tn}_{z u}}$ on $\sigma_{\mathrm{t}}$. Term A shows a tendency to shift from $0 \%$ to $50 \%$ with a decreasing Tn concentration ratio $C_{\mathrm{Tn}_{z_{1}}} / C_{\mathrm{Tn}_{z_{\mathrm{u}}}}$ (Fig. 13). For example, during periods with $C_{\mathrm{Tn}_{z_{1}}} / C_{\mathrm{Tn}_{z_{\mathrm{u}}}}$ ratios below 2.5 , the terms A and B contribute to the total uncertainty with about $30-50 \%$ and $70-50 \%$, respectively. In contrast, under conditions when the $C_{\mathrm{Tn}_{z_{1}}} / C_{\mathrm{Tn}_{z_{\mathrm{u}}}}$ ratio is higher than 2.5 , term B can account for up to $100 \%$ to the total uncertainty. In other words, in cases when the Tn concentration at the upper measurement height is very small, the error in the calculated value of $\tau$ is dominated by errors in the upper measurement height. We found that term $C$ can reduce the sum of term A and B by $0-43 \%$ for our data set (not shown), and strongly depends on the correlation coefficient $r_{\left(C_{\mathrm{Tn}_{\mathrm{z}}}, C_{\mathrm{Tn}_{z \mathrm{u}}}\right)}$ of the measured Tn concentrations at the two heights.

\section{Summary and conclusions}

We present and characterize a novel automated system for the measurement of vertical Tn and Rn profiles near the ground. In contrast to most previous studies, we perform continuous measurements with one single instrument per inlet height using commercially available monitors (RAD7) that are selective for Tn and Rn. Hence, the major progress of the system is its suitability for the direct determination of the incanopy transport time from vertical $\mathrm{Tn}$ concentration differences. We found that the system, including optimized chambers, alpha detectors and flows, is suitable to detect vertical differences of $\mathrm{Tn}$ and also those of $\mathrm{Rn}$ close to a relatively 
strong source (e.g., in low canopies). The performance of the system was investigated by considering (a) residence times of the air in the system, including the effect of filter clogging, (b) validation of the Tn sensitivity using a primary standard, (c) determination of the limits of detection, and (d) a rigorous determination of systematic and random errors for Tn concentrations measured under field conditions. These achievements were the prerequisite to analyze the inlet height arrangements required to obtain a high data quality. The system was operated during an intensive field campaign for two months at a natural grassland ecosystem. Vertical concentration profiles of $\mathrm{Tn}$ and $\mathrm{Rn}$ for two periods with different inlet height arrangements are presented. For the first time, we calculate transport times $(\tau)$ directly from selectively measured $\mathrm{Tn}$ concentration profiles and propagate the uncertainty of the in-canopy transport time $\left(\sigma_{\tau}\right)$ from the random $\mathrm{Tn}$ concentration errors $\left(\sigma C_{\mathrm{Tn}}\right)$. The averaged $\sigma C$ for $\mathrm{Tn}$ and Rn was determined to be $\sigma C_{\mathrm{Tn}}=\frac{0.10 C+13.2 \mathrm{~Bq} \mathrm{~m}^{-3}}{\sqrt{2}}$ and $\sigma C_{\mathrm{Rn}}=\frac{0.19 C+9.5 \mathrm{~Bq} \mathrm{~m}^{-3}}{\sqrt{2}}$. A quality assessment of the transport times revealed a good data quality with relative uncertainties below $50 \%$ for $44 \%$ of all determined transport times during the field experiment. The occasional occurrence of transport time uncertainties higher than $100 \%$ are related to measured absolute Tn gradients below $70 \mathrm{~Bq} \mathrm{~m}^{-3} \mathrm{~m}^{-1}$ and occur for $22 \%$ of all calculated transport times. Large gradients cause smaller relative transport time errors. In addition, the method appears highly sensitive to the Tn concentration measured in the upper height $\left(C_{\mathrm{Tn}_{z \mathrm{u}}}\right)$. Low values of $C_{\mathrm{Tn}_{z \mathrm{u}}}$ result in high absolute values of $\sigma_{\tau}$. An analysis of the contribution of individual error propagation terms to $\sigma_{\tau}$ underlines these findings. It should be noted that to obtain large gradients, it is preferable to increase the vertical separation of the measurement heights. For Rn, this is possible to some extent since $C_{\mathrm{Rn}_{z u}}$ decreases only as a result of dilution by turbulence. However, the vertical inlet separation is much more limited for the determination of the transport time by the fast Tn decay due to sharply decreasing values of $C_{\text {Tn }}$ with height. Consequently, the analyzer with the best precision should always be placed in the uppermost height, whose position has to be chosen very carefully. The major requirement for the future is the improvement of the RAD7 precision at low concentrations, which implies a decrease of the LOD. This might be achieved by further increasing the size of the measurement chamber as well as the active surface area of the alpha detectors.

Our setup allows the quantification of $\tau$ within the grass canopy for different layers. The transport times may subsequently be converted into a vertical profile of bulk diffusion coefficients. Our results provide an excellent basis for a reliable investigation of turbulence-chemistry interactions (e.g., Damköhler number) in canopies. The uncertainties of $\tau$ values determined with the Tn or Rn method should be considered for the interpretation of results in further studies.
Acknowledgements. This project was funded by the Max Planck Society. We are grateful to $\mathrm{H}$. Gross for the electrical installations at the field site and for logistical support. We thank D. Lane-Smith for discussing the setup of the system and M. Flanz at the electronic department of MPIC for support with the data acquisition. We are indebted to A. Röttger at the Physikalisch-Technische Bundesanstalt (PTB, Braunschweig, Germany) for her help in validating the sensitivity of the RAD7 monitors for thoron.

The service charges for this open access publication have been covered by the Max Planck Society.

Edited by: P. Herckes

\section{References}

Brost, R. A. and Chatfield, R. B.: Transport of Radon in a 3Dimensional, Subhemispheric Model, J. Geophys. Res.-Atmos., 94, 5095-5119, doi:10.1029/Jd094id04p05095, 1989.

Butterweck, G., Reineking, A., Kesten, J., and Porstendörfer, J.: The Use of the Natural Radioactive Noble-Gases Radon and Thoron as Tracers for the Study of Turbulent Exchange in the Atmospheric Boundary-Layer - Case-Study in and above a Wheat Field, Atmos. Environ., 28, 1963-1969, 1994.

Cantrell, C. A.: Technical Note: Review of methods for linear leastsquares fitting of data and application to atmospheric chemistry problems, Atmos. Chem. Phys., 8, 5477-5487, doi:10.5194/acp8-5477-2008, 2008.

Currie, L. A.: Limits for Qualitative Detection and Quantitative Determination - Application to Radiochemistry, Anal. Chem., 40, 586-593, doi:10.1021/ac60259a007, 1968.

De Arellano, J., Duynkerke, P. G., and Builtjes, P. J. H.: The Divergence of the Turbulent-Diffusion Flux in the Surface-Layer Due to Chemical-Reactions - the NO-O $-\mathrm{NO}_{2}$ System, Tellus B, 45, 23-33, doi:10.1034/j.1600-0889.1993.00002.x, 1993.

Denmead, O. T. and Bradley, E. F.: Flux-Gradient Relationships in a Forest Canopy, in: The Forest-Atmosphere Interaction, edited by: Hutchinson, B. A. and Hicks, B. B., Reidel, Dordrecht, 421 pp., 1985.

Dlugi, R., Berger, M., Zelger, M., Hofzumahaus, A., Siese, M., Holland, F., Wisthaler, A., Grabmer, W., Hansel, A., Koppmann, R., Kramm, G., Möllmann-Coers, M., and Knaps, A.: Turbulent exchange and segregation of $\mathrm{HO}_{\mathrm{x}}$ radicals and volatile organic compounds above a deciduous forest, Atmos. Chem. Phys., 10, 6215-6235, doi:10.5194/acp-10-6215-2010, 2010.

Dorr, H., Kromer, B., Levin, I., Munnich, K. O., and Volpp, H. J.: $\mathrm{CO}_{2}$ and Radon 222 as Tracers for Atmospheric Transport, J. Geophys. Res.-Ocean, 88, 1309-1313, 1983.

Finnigan, J.: Turbulence in plant canopies, Annu. Rev. Fluid. Mech., 32, 519-571, doi:10.1146/annurev.fluid.32.1.519, 2000.

Foken, T.: Micrometeorology, Springer, Berlin, Heidelberg, 306 pp., 2008.

Gut, A., Scheibe, M., Rottenberger, S., Rummel, U., Welling, M., Ammann, C., Kirkman, G. A., Kuhn, U., Meixner, F. X., Kesselmeier, J., Lehmann, B. E., Schmidt, W., Muller, E., and Piedade, M. T. F.: Exchange fluxes of $\mathrm{NO}_{2}$ and O-3 at soil and leaf surfaces in an Amazonian rain forest, J. Geophys. Res.Atmos., 107, 8060, doi:10.1029/2001JD000654, 2002. 
Hänsel, H. and Neumann, W.: Physik, Spectrum, Akad. Verl., Heidelberg, Berlin, Oxford, 1995.

Hens, K.: Der bodennahe, vertikale, turbolente Transport von ${ }^{222} \mathrm{Rn},{ }^{220} \mathrm{Rn}$ und anderen Spurengasen im Stammraum eines Fichtenbestandes, Diplom, Institut für Physik, Johannes Gutenberg - Universität, Mainz, 93 pp., 2009 (in German).

Ikebe, Y. and Shimo, M.: Estimation of Vertical Turbulent Diffusivity from Thoron Profiles, Tellus, 24, 29-37, doi:10.1111/j.21533490.1972.tb01530.x, 1972.

Israel, G. W.: Thoron (Rn220) Measurements in the Atmosphere and their application in meteorology, Tellus B, 17, 383-388, 1965.

Lehmann, B. E., Lehmann, M., Neftel, A., Gut, A., and Tarakanov, S. V.: Radon-220 calibration of near-surface turbulent gas transport, Geophys. Res. Lett., 26, 607-610, 1999.

Lide, D. R.: CRC handbook of chemistry and physics : a readyreference book of chemical and physical data, 85th Edn., CRC Press, Boca Raton [u.a.], 2589 pp., 2004.

Liu, S. C., McAfee, J. R., and Cicerone, R. J.: Radon 222 and Tropospheric Vertical Transport, J. Geophys. Res., 89, 7291-7297, 1984.

Martens, C. S., Shay, T. J., Mendlovitz, H. P., Matross, D. M., Saleska, S. R., Wofsy, S. C., Woodward, W. S., Menton, M. C., De Moura, J. M. S., Crill, P. M., De Moraes, O. L. L., and Lima, R. L.: Radon fluxes in tropical forest ecosystems of Brazilian Amazonia: night-time $\mathrm{CO}_{2}$ net ecosystem exchange derived from radon and eddy covariance methods, Global Change Biol., 10, 618-629, 2004.

Mauder, M. and Foken, T.: Documentation and Instruction Manual of the Eddy-Covariance Software Package TK3, Arbeitsergebnisse Nr. 46, 2011.

Nemitz, E., Loubet, B., Lehmann, B. E., Cellier, P., Neftel, A., Jones, S. K., Hensen, A., Ihly, B., Tarakanov, S. V., and Sutton, M. A.: Turbulence characteristics in grassland canopies and implications for tracer transport, Biogeosciences, 6, 1519-1537, doi:10.5194/bg-6-1519-2009, 2009.

Pape, L., Ammann, C., Nyfeler-Brunner, A., Spirig, C., Hens, K., and Meixner, F. X.: An automated dynamic chamber system for surface exchange measurement of non-reactive and reactive trace gases of grassland ecosystems, Biogeosciences, 6, 405429, doi:10.5194/bg-6-405-2009, 2009.

Personne, E., Loubet, B., Herrmann, B., Mattsson, M., Schjoerring, J. K., Nemitz, E., Sutton, M. A., and Cellier, P.: SURFATM-NH3: a model combining the surface energy balance and bi-directional exchanges of ammonia applied at the field scale, Biogeosciences, 6, 1371-1388, doi:10.5194/bg-6-1371-2009, 2009.

Röttger, A. and Honig, A.: Recent Developments in Radon Metrology: New Aspects in the Calibration of Radon, Thoron and Progeny Devices, Radiat. Prot. Dosim., 145, 260-266, doi:10.1093/Rpd/Ncr047, 2011.
Sanderson, M. G., Collins, W. J., Derwent, R. G., and Johnson, C. E.: Simulation of global hydrogen levels using a lagrangian three-dimensional model, J. Atmos. Chem., 46, 15-28, doi:10.1023/A:1024824223232, 2003.

Simon, E., Lehmann, B. E., Ammann, C., Ganzeveld, L., Rummel, U., Meixner, F. X., Nobre, A. D., Araujo, A., and Kesselmeier, J.: Lagrangian dispersion of $\mathrm{Rn}-222, \mathrm{H}_{2} \mathrm{O}$ and $\mathrm{CO}_{2}$ within Amazonian rain forest, Agr. Forest Meteorol., 132, 286-304, 2005.

Staudt, K., Serafimovich, A., Siebicke, L., Pyles, R. D., and Falge, E.: Vertical structure of evapotranspiration at a forest site (a case study), Agr. Forest Meteorol., 151, 709-729, doi:10.1016/j.agrformet.2010.10.009, 2011.

Taylor, J. R.: An Introduction to Error Analysis. The Study of Unvertainties in Physical Measurements, University Science Books, Sausalito, California, 1997.

Thom, A. S.: Momentum, Mass and Heat Exchange of Plant Communities, in: Vegetation and the Atmosphere, edited by: Monteith, J. L., Academic Press, London, 57-109, 1975.

Trumbore, S. E., Keller, M., Wofsy, S. C., and Dacosta, J. M.: Measurements of Soil and Canopy Exchange-Rates in the Amazon Rain-Forest Using Rn-222, J. Geophys. Res.-Atmos., 95, 1686516873, 1990.

Ussler, W., Chanton, J. P., Kelley, C. A., and Martens, C. S.: Radon222 Tracing of Soil and Forest Canopy Trace Gas-Exchange in an Open Canopy Boreal Forest, J. Geophys. Res.-Atmos., 99, 19531963, 1994.

van Pul, W. A. J. and Jacobs, A. F. G.: The Conductance of a Maize Crop and the Underlying Soil to Ozone under Various Environmental-Conditions, Bound.-Lay. Meteorol., 69, 83-99, 1994.

Wada, A., Murayama, S., Kondo, H., Matsueda, H., Sawa, Y., and Tsuboi, K.: Development of a Compact and Sensitive Electrostatic Radon-222 Measuring System for Use in Atmospheric Observation, J. Meteorol. Soc. Jpn., 88, 123-134, doi:10.2151/jmsj.2010-202, 2010.

Wolff, V., Trebs, I., Ammann, C., and Meixner, F. X.: Aerodynamic gradient measurements of the $\mathrm{NH}_{3}-\mathrm{HNO}_{3}-\mathrm{NH}_{4} \mathrm{NO}_{3}$ triad using a wet chemical instrument: an analysis of precision requirements and flux errors, Atmos. Meas. Tech., 3, 187-208, doi:10.5194/amt-3-187-2010, 2010.

Yienger, J. J. and Levy, H.: Empirical-Model of Global SoilBiogenic Nox Emissions, J. Geophys. Res.-Atmos., 100, 1144711464, doi:10.1029/95jd00370, 1995.

Zahorowski, W., Chambers, S. D., and Henderson-Sellers, A.: Ground based radon-222 observations and their application to atmospheric studies, J. Environ. Radioactiv., 76, 3-33, 2004.

Zhang, K., Wan, H., Zhang, M., and Wang, B.: Evaluation of the atmospheric transport in a GCM using radon measurements: sensitivity to cumulus convection parameterization, Atmos. Chem. Phys., 8, 2811-2832, doi:10.5194/acp-8-2811-2008, 2008. 